in vivo 35 : 929-935 (2021)

doi:10.21873/invivo.12333

\title{
Prognostic Role of Lung Immune Scores for Prediction of Survival in Limited-stage Small Cell Lung Cancer
}

\author{
LEON SCHNÖLLER $^{1 *}$, LUKAS KÄSMANN $^{1,2,3^{*}}$, JULIAN TAUGNER ${ }^{1}$, \\ REEM ABDO $^{1}$, CHUKWUKA EZE $^{1}$ and FARKHAD MANAPOV ${ }^{1,2,3}$ \\ ${ }^{1}$ Department of Radiation Oncology, University Hospital, LMU Munich, Munich, Germany; \\ ${ }^{2}$ Comprehensive Pneumology Center Munich (CPC-M), \\ Member of the German Center for Lung Research (DZL), Munich, Germany; \\ ${ }^{3}$ German Cancer Consortium (DKTK), Partner Site Munich, Munich, Germany
}

\begin{abstract}
Background/Aim: Previous studies have suggested the prognostic value of the Lung Immune Prediction Index (LIPI) and the Gustave Roussy Score (GRIM) as prognostic markers in advanced small cell lung cancer (SCLC). However, LIPI and GRIM score have not been evaluated in patients with limited stage SCLC (LSSCLC). Patients and Methods: Pretreatment LIPI and GRIM score of 33 (43\%) patients out of 77 LS-SCLC patients treated with chemoradiotherapy (CRT) during 2004-2015 were included. Results: The median overall survival (OS) time in the good, intermediate, and poor LIPI subgroups were 14,17 and 3 months $(p=0.973)$ and 14,17 and 17 months in the GRIM subgroups. In univariate analysis, patients age $<65$ years $(p=0.008)$, concurrent chemotherapy $(p=0.028)$, and administering prophylactic cranial irradiation $(P C I)(p=0.031)$ were associated with improved OS. Using Cox regression analysis, age remained significant $(H R=3.299, p=0.031)$ and PCI showed a trend (HR=2.801, $p=0.06)$. Conclusion: Independent predictors of overall survival were identified and can contribute to improved treatment personalization. Concurrent chemotherapy and PCI after CRT were associated with improved OS compared to LIPI- and GRIM-score, which had no prognostic impact in $L S$-SCLC.
\end{abstract}

This article is freely accessible online.

*These Authors contributed equally to this study.

Correspondence to: Lukas Käsmann, Department of Radiation Oncology, University Hospital (LMU), Marchioninistraße 15, 81377 Munich, Germany. Tel: +49 89440073770, Fax: +49 89440076770, e-mail: Lukas.Kaesmann@med.uni-muenchen.de

Key Words: SCLC, chemoradiotherapy, survival, prognostic factor, blood parameters, immune scores.
Small cell lung cancer (SCLC) is a highly aggressive cancer subtype with a rapid doubling time, early metastases, and dismal prognosis. State-of-the-art treatment of limited-stage SCLC (LSSCLC) patients compromises definitive chemoradiotherapy (CRT) followed by prophylactic cranial irradiation (PCI) (1-7). Particular attention should be paid to patients with severe comorbidities, reduced performance status, or advanced age, as intensive treatment is not tolerated (8). However, selected patients may need therapy intensification in order to improve local and distant control. Hence for patient-centered therapy decision-making, individual clinical parameters such as gender, age, performance status, and smoking habit must be considered (1). Systemic inflammation seems to be involved in tumor promotion and progression. Markers of systemic inflammation are associated with a poor outcome and can be used for risk stratification (9). Several novel and clinically-practical parameters have been introduced as independent prognostic factors, such as the Lung Immune Prognostic Index (LIPI), the Gustave Roussy Immune Score (GRIM-Score), the NeutrophilLymphocyte Ratio (NLR) and the derived NeutrophilLymphocyte Ratio (dNLR) (9-11). The prognostic role of the GRIM and LIPI scores in non-small cell lung cancer (NSCLC) regarding OS and progression-free survival (PFS) as well as their importance as predictive indicators of treatment response to immunotherapy with immune checkpoint inhibitors (ICIs) has already been validated $(12,13)$. However, to the best of our knowledge, there are no studies on the prognostic value of the GRIM- and LIPI-score in LS-SCLC patients yet. In the present study, we aimed to validate the prognostic value of the LIPI and GRIM scores in patients with LS-SCLC receiving platinum-based CRT.

\section{Patients and Methods}

Study population. The medical charts of 77 consecutive patients with LS-SCLC that were treated with curative-intent platinum-based chemoradiotherapy between 01/2004 and 12/2015 were assessed. After excluding patients with unknown blood parameters before 
Table I. Patient and treatment characteristics.

\begin{tabular}{|c|c|}
\hline & $\mathrm{N}(\%)$ \\
\hline Total & $33(100)$ \\
\hline \multicolumn{2}{|l|}{ Age } \\
\hline Median years & 63 \\
\hline$\geq 65$ years & $15(45)$ \\
\hline \multicolumn{2}{|l|}{ Gender } \\
\hline Male & $13(39)$ \\
\hline Female & $20(61)$ \\
\hline \multicolumn{2}{|l|}{ T-stage } \\
\hline 1 & $4(12)$ \\
\hline 2 & $9(27)$ \\
\hline 3 & $8(24)$ \\
\hline 4 & $12(36)$ \\
\hline \multicolumn{2}{|l|}{$\mathrm{N}$-category } \\
\hline 0 & $1(3)$ \\
\hline 1 & $2(6)$ \\
\hline 2 & $18(55)$ \\
\hline 3 & $12(36)$ \\
\hline \multicolumn{2}{|l|}{ Karnofsky performance status } \\
\hline $80-100 \%$ & $29(88)$ \\
\hline $50-70 \%$ & $4(12)$ \\
\hline \multicolumn{2}{|l|}{ Concurrent chemotherapy } \\
\hline Yes & $18(55)$ \\
\hline No & $15(46)$ \\
\hline \multicolumn{2}{|l|}{ Radiation regimen } \\
\hline Once daily & $24(73)$ \\
\hline Twice daily & $9(27)$ \\
\hline \multicolumn{2}{|l|}{ Prophylactic cranial irradiation } \\
\hline Yes & $24(73)$ \\
\hline No & $9(27)$ \\
\hline \multicolumn{2}{|l|}{ NLR } \\
\hline$<3$ & $23(70)$ \\
\hline$\geq 3$ & $10(30)$ \\
\hline \multicolumn{2}{|l|}{ dNLR } \\
\hline$<3$ & $9(27)$ \\
\hline$\geq 3$ & $24(73)$ \\
\hline \multicolumn{2}{|l|}{ Gustave Roussy Immune Score } \\
\hline Favorable prognostic group & $19(58)$ \\
\hline Intermediate prognostic group & $11(33)$ \\
\hline Poor prognostic group & $3(9)$ \\
\hline \multicolumn{2}{|l|}{ The Lung Immune Prognostic Index } \\
\hline Favorable prognostic group & $21(64)$ \\
\hline Intermediate prognostic group & $10(30)$ \\
\hline Poor prognostic group & $2(6)$ \\
\hline
\end{tabular}

NLR: Neutrophil-lymphocyte Ratio; dNLR: derived neutrophillymphocyte ratio.

initiation of radiotherapy, $33(43 \%)$ patients remained and were included in the analysis. Patient and treatment characteristics are summarized in Table I. Patients received a median radiation dose in equivalent dose of 2Gy fractions (EQD2) of 59 (range:42-67) Gy or were treated with hyperfractionated accelerated radiotherapy (14). $55 \%$ of all patients were treated with concurrent platinum-based chemotherapy. PCI was administered after the end of thoracic irradiation in $73 \%$ of all patients. The Institutional Research Ethical Review Board approved the study (approval number: 17-230).
Assessment of immune scores based on blood cell counts. Blood parameters of all patients were assessed and included lymphocyte count, leucocyte count, neutrophil count, neutrophil-to-lymphocyte ratio (NLR), derived NLR (defined as neutrophils/(leucocytesneutrophils) ratio), LDH and serum albumin levels. For our analysis, we chose the latest blood values before the initiation of radiotherapy (up to two weeks before treatment start). The calculation of the GRIM score is based on the neutrophil to leukocyte ratio (NLR) $(>6)$, the lactate dehydrogenase $(\mathrm{LDH})>$ upper limit of normal $(\mathrm{ULN})$, and the serum albumin (ALB) concentration $(<3.5)(15)$. The Lung Immune Prognostic Index (LIPI) includes the blood levels LDH $>$ ULN and the derived NLR (dNLR: neutrophils/[leucocytesneutrophils]), $>3$ of pretreated patients and stratifies patients into "poor," "intermediate," and "good" prognostic groups (16).

Statistical analysis. Statistical analyses were performed using SPSS statistics 25 (IBM, New York, USA) and R version 3.5.3. Subgroups were compared using the log-rank test. All significant variables in univariate analysis were included in a multivariate Cox regression analysis. The proportional hazard assumption of the Cox regression analysis was tested. Overall survival was defined as the time between the last day of radiotherapy and death. For all statistical analyses, a significance level of $\alpha=0.05$ was defined.

\section{Results}

Median survival time in our patient cohort was 17 months (range $=2-44$ months). 1- and 2-year-survival rates were 58\% and $36 \%$, respectively (Table II). Median survival in the good, intermediate, and poor LIPI subgroup was 14,17 and 3 months $(p=0.973)$. Median survival of the GRIM subgroups was 14,17 , and 17 months in the favorable, intermediate, and poor prognosis group $(p=0.984)$. In univariate analysis, patients with an age of $<65$ years, patients treated with concurrent chemotherapy, and patients receiving PCI after chemoradiotherapy showed improved overall survival (median OS=11 vs. 36 months $(p=0.008), 12 v s .36$ months $(p=0.028)$ and 12 vs. 20 months $(p=0.031)$ (Figure 1a-c). In multivariate analysis, age was found to be an independent prognostic factor (hazard ratio $(\mathrm{HR})=3.299,95 \%$ confidence interval $(\mathrm{CI})=1.119-9.726, \quad p=0.031)$, concurrent platinum-based chemotherapy $(\mathrm{HR}=1.101,95 \% \mathrm{CI}=0.328-3.702, p=0.876)$ and PCI after chemoradiotherapy $(\mathrm{HR}=2.801,95 \% \mathrm{CI}=0.956$ 8.197, $p=0.06$ ) were not.

\section{Discussion}

Our study aimed to validate the GRIM and LIPI score for patients with LS-SCLC undergoing CRT. The objective was driven by the fact that cancer immunology has recently gained increasing importance in the treatment of SCLC. Although a combination therapy of platinum-etoposide chemotherapy and thoracic radiotherapy has remained the first-line treatment for LS-SCLC for more than 20 years, ICIs have been approved for certain indications in SCLC, especially extensive or recurrent SCLC (14). The CASPIAN trial found that first-line therapy 
Table II. Univariate and multivariate analysis of overall survival based on clinicopathological characteristics.

\begin{tabular}{|c|c|c|c|c|}
\hline & $\begin{array}{l}12 \text { months } \\
\text { survival rate }(\%)\end{array}$ & $\begin{array}{l}24 \text { months } \\
\text { survival rate }(\%)\end{array}$ & $\begin{array}{c}p \text {-value } \\
\text { (univariate analysis) }\end{array}$ & $\begin{array}{c}p \text {-value } \\
\text { (multivariate analysis) }\end{array}$ \\
\hline \multicolumn{5}{|l|}{ Age } \\
\hline$<65$ years & 72 & 56 & & \\
\hline$\geq 65$ years & 40 & 13 & 0.008 & 0.031 \\
\hline \multicolumn{5}{|l|}{ Gender } \\
\hline Male & 46 & 31 & & \\
\hline Female & 65 & 40 & 0.302 & \\
\hline \multicolumn{5}{|l|}{ T-stage } \\
\hline $1-2$ & 50 & 25 & & \\
\hline $3-4$ & 59 & 38 & 0.358 & \\
\hline \multicolumn{5}{|l|}{$\mathrm{N}$-category } \\
\hline $0-1$ & 67 & 0 & & \\
\hline $2-3$ & 57 & 40 & 0.296 & \\
\hline \multicolumn{5}{|l|}{ Karnofsky performance status } \\
\hline $80-100 \%$ & 62 & 38 & & \\
\hline $50-70 \%$ & 25 & 25 & 0.246 & \\
\hline \multicolumn{5}{|l|}{ Concurrent chemotherapy } \\
\hline Yes & 67 & 56 & & \\
\hline No & 47 & 13 & 0.028 & 0.876 \\
\hline \multicolumn{5}{|l|}{ Radiation regimen } \\
\hline Once daily & 54 & 29 & & \\
\hline Twice daily & 67 & 56 & 0.246 & \\
\hline \multicolumn{5}{|l|}{ Prophylactic cranial irradiation } \\
\hline Yes & 63 & 46 & & \\
\hline No & 44 & 11 & 0.031 & 0.060 \\
\hline \multicolumn{5}{|l|}{ NLR } \\
\hline$<3$ & 65 & 35 & & \\
\hline$\geq 3$ & 40 & 40 & 0.634 & \\
\hline \multicolumn{5}{|l|}{ dNLR } \\
\hline$<3$ & 63 & 33 & & \\
\hline$\geq 3$ & 44 & 33 & 0.725 & \\
\hline \multicolumn{5}{|l|}{ Gustave Roussy Immune Score } \\
\hline Favorable prognostic group & 58 & 37 & & \\
\hline Intermediate prognostic group & 55 & 36 & & \\
\hline Poor prognostic group & 67 & 33 & 0.984 & \\
\hline \multicolumn{5}{|l|}{ The Lung Immune Prognostic Index } \\
\hline Favorable prognostic group & 52 & 33 & & \\
\hline Intermediate prognostic group & 70 & 40 & & \\
\hline Poor prognostic group & 50 & 50 & 0.973 & \\
\hline
\end{tabular}

$p$-value of univariate analysis was calculated by log-rank test; $p$-value of significant variables in univariate analysis was calculated by multivariate Cox regression analysis. NLR: Neutrophil-lymphocyte ratio; dNLR: derived neutrophil-lymphocyte ratio.

with durvalumab plus platinum-etoposide chemotherapy improved OS in extensive stage SCLC compared to standard chemotherapy (18). The CheckMate 032 phase I/II trial has shown that nivolumab monotherapy is an effective option for third-line therapy of recurrent SCLC (19). Patients with recurrent or metastatic SCLC who had undergone at least two previous therapy lines could further benefit from pembrolizumab regardless of PD-L1 expression (20). Implementation of ICIs in LS-SCLC is currently under investigation (30, 31). A randomized Phase II/III clinical trial (NCT03811002/NRG-LU005) evaluates the standard treatment compared to chemoradiotherapy plus atezolizumab (30). In addition, a randomized controlled multicenter study (NCT03703297/ADRIATIC) currently investigates consolidation treatment with durvalumab or durvalumab in combination with tremelimumab in LS-SCLC patients without disease progression after CRT (31). In this context, prognostic prediction tools such as the NLR, LIPI, and GRIM score could be helpful in order to tailor treatment individualization and predict outcome. The GRIM score was initially developed to select suitable patients for phase I trials of ICIs, and the LIPI score is designed to predict response to immunotherapy, guide treatment selection, and identify those patients who are unlikely to benefit from ICIs $(13,15,16)$. In ED-SCLC, the GRIM-score can serve as a 
A

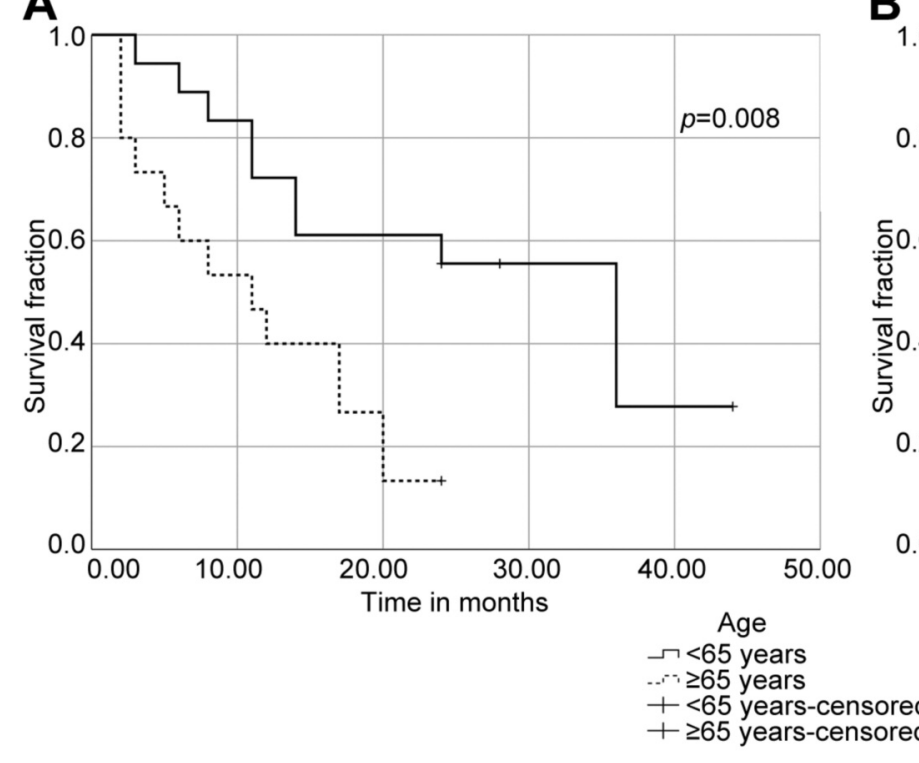

B

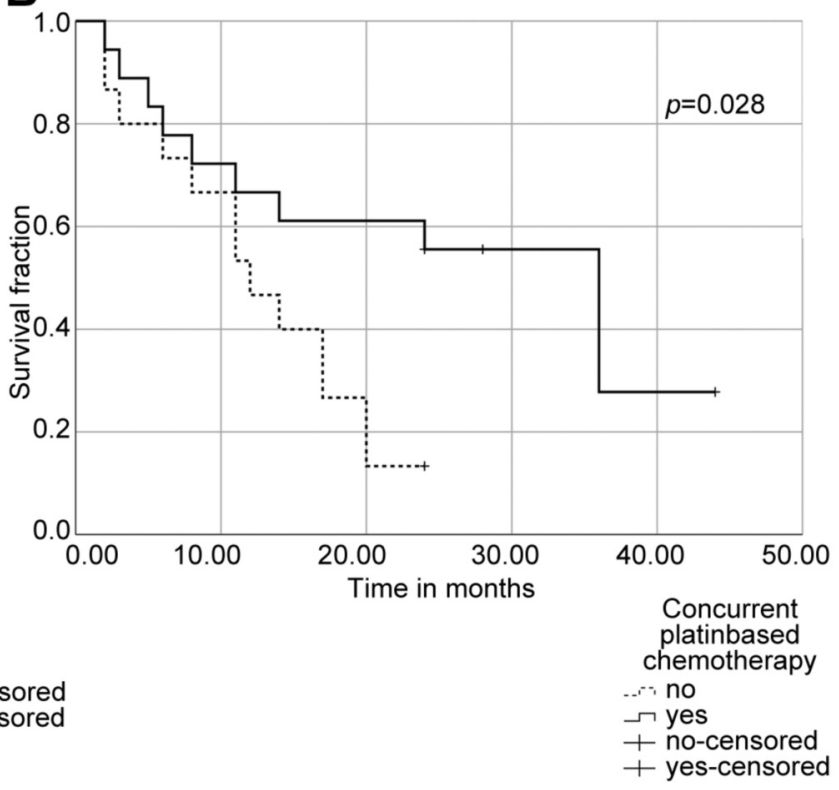

C

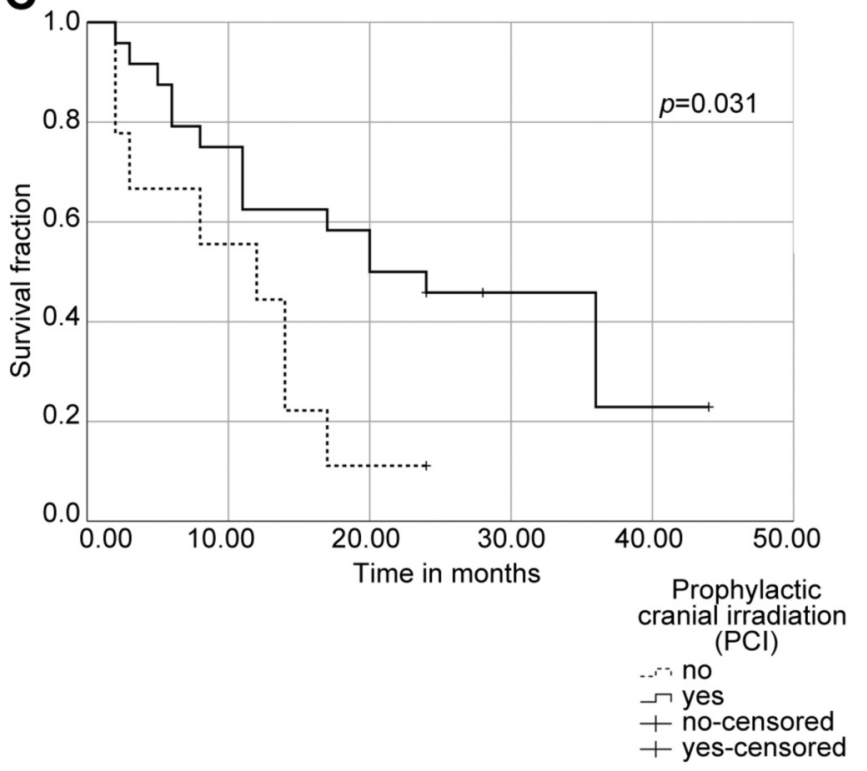

Figure 1. Overall survival for limited-stage small cell lung cancer (LS-SCLC) patients undergoing curative-intent chemoradiotherapy using KaplanMeier analysis and log-rank test. (A) Kaplan-Meier survival curve for overall survival according to age groups. (B) Kaplan-Meier survival curve for overall survival regarding concurrent platinum-based chemotherapy. (C) Kaplan-Meier survival curve for overall survival (OS) regarding prophylactic cranial irradiation (PCI).

reliable prognostic factor of OS (10). In non-small cell lung cancer (NSCLC), the prognostic impact of the GRIM-Score has also been investigated in earlier stages (operable stage I and II NSCLC) (21). Nakaya et al. report that the NLR during treatment of advanced NSCLC with nivolumab could be a predictive marker of treatment response or PFS. However, no pre-treatment marker could be identified (24). Another study conducted by Suh et al. reported that a high NLR $(\geq 5)$ at six weeks after treatment with anti-PD-1 antibody is associated with inferior PFS in patients with advanced NSCLC (25). An Italian study with two centers including 120 patients with SCLC and large cell neuroendocrine carcinoma (LCNEC) showed that the LIPI score allowed for patient stratification into good (15 months), intermediate (11 months) and poor (9 
months) groups according to their median OS (23). The baseline of both scores is the NLR, which reflects the inflammatory balance and can serve as a prognostic biomarker of OS and PFS. Our study found no prognostic relevance of the GRIM- and LIPI-Score for LS-SCLC. Instead, our study supports the treatment with concurrent platinum-based chemotherapy and PCI after CRT. Moreover, we found that age is an independent prognostic factor in the treatment of LSSCLC, thereby emphasizing the importance of patient-centered therapy assessment. Age should be considered together with gender, Karnofsky performance score, tumor stage, hemoglobin level, and comorbidity scale in order to improve treatment individualization and shared-decision making (26-28).

Several limitations need to be considered such as the retrospective design and small sample size which may have led to selection bias and therefore need to be critically considered. Moreover, not all patients of the recruitment period could be included due to unknown pretreatment blood parameters. Consequently, alternative conclusions could be found in larger retrospective or randomized prospective studies. Despite these limitations, this is the first study to provide an initial assessment of the prognostic relevance of LIPI and GRIM scores in LSSCLC. Although the GRIM and LIPI scores in our study showed no prognostic impact on the treatment of LS-SCLC, our data are consistent with recent studies. Concurrent platinumbased chemotherapy and administering PCI after CRT are associated with improved survival, and patient age is an independent prognostic factor of high clinical relevance for risk stratification.

\section{Conclusion}

Age is an independent prognostic factor in the treatment of LS-SCLC and should be critically considered in treatment allocation. Administration of concurrent chemotherapy and PCI after the end of CRT were associated with improved OS compared to pretreatment LIPI- and GRIM-score which had no significant impact. The results of ongoing trials investigating immune checkpoint inhibition in LS-SCLC are eagerly awaited. Pretreatment LIPI- and GRIM-score may serve as prognostic biomarkers in these studies and should be evaluated in multimodal treatment including immune checkpoint inhibition for LS-SCLC.

\section{Conflicts of Interest}

The Authors declare that there is no conflict of interest.

\section{Authors' Contributions}

LS, LK and RA were involved in the conceptualization of the project, data collection and text drafting. JT, RA, CE and FM critically reviewed and edited the text. LK and RA visualized the data and performed the statistical analysis. FM and LK had the supervision.

\section{References}

1 Früh M, De Ruysscher D, Popat S, Crinò L, Peters S and Felip E: Small-cell lung cancer (SCLC): ESMO clinical practice guidelines for diagnosis, treatment and follow-up. Ann Oncol 24(6): vi99-vi105, 2013. PMID: 23813929. DOI: 10.1093/ annonc/mdt178

2 Chen Y, Li J, Zhang Y, Hu Y, Zhang G, Yan X, Lin Z, Zhao Z and Jiao $S$ : Early versus late prophylactic cranial irradiation in patients with extensive small cell lung cancer. Strahlenther Onkol 194: 876-885, 2018. PMID: 29774395. DOI: 10.1007/ s00066-018-1307-1

3 Eze C, Käsmann L and Manapov F: Redefining the role of prophylactic cranial irradiation in the modern era of active surveillance in small cell lung cancer. JAMA Oncol 5: 11-12, 2019. PMID: 30422210. DOI: 10.1001/jamaoncol.2018.4833

4 Eze C, Roengvoraphoj O, Niyazi M, Hildebrandt G, Fietkau R, Belka $\mathrm{C}$ and Manapov F: Treatment response and prophylactic cranial irradiation are prognostic factors in a real-life limiteddisease small-cell lung cancer patient cohort comprehensively staged with cranial magnetic resonance imaging. Clin Lung Cancer 18: e243-e249, 2017. PMID: 28065620. DOI: 10.1016/ j.cllc.2016.11.005

5 Eze C, Roengvoraphoj O, Dantes M, Abdo R, Käsmann L, Schmidt-Hegemann NS, Belka C and Manapov F: Prophylactic cranial irradiation for patients with small cell lung cancer in Germany: Pattern of care survey. Anticancer Res 38: 5261-5265, 2018. PMID: 30194176. DOI: 10.21873/anticanres.12851

6 Manapov F, Käsmann L, Roengvoraphoj O, Dantes M, SchmidtHegemann NS, Belka C and Eze C: Prophylactic cranial irradiation in small-cell lung cancer: Update on patient selection, efficacy and outcomes. Lung Cancer (Auckl) 9: 49-55, 2018. PMID: 30323698. DOI: 10.2147/LCTT.S137577

7 Manapov F, Eze C, Niyazi M, Roengvoraphoj O, Li M, Hegemann NS, Hildebrandt G, Fietkau R and Belka C: Investigating a correlation between chemoradiotherapy schedule parameters and overall survival in a real-life LD SCLC patient cohort. J Cancer 7: 2012-2017, 2016. PMID: 27877216. DOI: $10.7150 /$ jca. 16741

8 Semrau S, Zettl H, Hildebrandt G, Klautke G and Fietkau R: Ältere Patienten mit inoperablem nicht-kleinzelligem Bronchialkarzinom: Langzeitüberleben nach simultaner Chemoradiotherapie. Strahlenther Onkol 190: 1125-1132, 2014. PMID: 25098688. DOI: 10.1007/s00066-014-0710-5

9 Russo A, Russano M, Franchina T, Migliorino MR, Aprile G, Mansueto G, Berruti A, Falcone A, Aieta M, Gelibter A, Russo A, Barni S, Maio M, Martelli O, Pantano F, Iacono D, Calvetti L, Quadrini S, Roca E, Vasile E, Imperatori M, Occhipinti M, Galvano A, Petrelli F, Calabrò L, Pasquini G, Intagliata S, Ricciardi GRR, Tonini G, Santini D and Adamo V: Neutrophilto-lymphocyte ratio (NLR), platelet-to-lymphocyte ratio (PLR), and outcomes with nivolumab in pretreated non-small cell lung cancer (NSCLC): A large retrospective multicenter study. Adv Ther 37: 1145-1155, 2020. PMID: 32002809. DOI: 10.1007/ s12325-020-01229-w

10 Minami S, Ihara S and Komutab K: Gustave Roussy immune score and Royal Marsden Hospital prognostic score are prognostic markers for extensive disease of small cell lung cancer. World J Oncol 11: 98-105, 2020. PMID: 32494316. DOI: 10.14740/WJON1275 
11 Benitez JC, Recondo G, Rassy E and Mezquita L: The LIPI score and inflammatory biomarkers for selection of patients with solid tumors treated with checkpoint inhibitors. Q J Nucl Med Mol Imaging 64: 162-174, 2020. PMID: 32107903. DOI: $10.23736 / \mathrm{S} 1824-4785.20 .03250-1$

12 Minami S, Ihara S, Ikuta S and Komuta K: Gustave Roussy immune score and Royal Marsden Hospital prognostic score are biomarkers of immune-checkpoint inhibitor for non-small cell lung cancer. World J Oncol 10: 90-100, 2019. PMID: 31068989. DOI: $10.14740 /$ wjon 1193

13 Aldea M, Benitez JC and Mezquita L: The lung immune prognostic index (LIPI) stratifies prognostic groups in advanced non-small cell lung cancer (NSCLC) patients. Transl Lung Cancer Res 9: 967-970, 2020. PMID: 32953477. DOI: 10.21037/ tlcr.2020.04.14

14 Turrisi AT, Kim K, Blum R, Sause WT, Livingston RB, Komaki $\mathrm{R}$, Wagner H, Aisner S and Johnson DH: Twice-daily compared with once-daily thoracic radiotherapy in limited small-cell lung cancer treated concurrently with cisplatin and etoposide. N Engl J Med 340: 265-271, 1999. PMID: 9920950. DOI: 10.1056/ nejm199901283400403

15 Bigot F, Castanon E, Baldini C, Hollebecque A, Carmona A, Postel-Vinay S, Angevin E, Armand JP, Ribrag V, Aspeslagh S, Varga A, Bahleda R, Menis J, Gazzah A, Michot JM, Marabelle A, Soria JC and Massard C: Prospective validation of a prognostic score for patients in immunotherapy phase I trials: The Gustave Roussy immune score (GRIm-Score). Eur J Cancer 84: 212-218, 2017. PMID: 28826074. DOI: 10.1016/j.ejca.2017.07.027

16 Mezquita L, Auclin E, Ferrara R, Charrier M, Remon J, Planchard D, Ponce S, Ares LP, Leroy L, Audigier-Valette C, Felip E, Zerón-Medina J, Garrido P, Brosseau S, Zalcman G, Mazieres J, Caramela C, Lahmar J, Adam J, Chaput N, Soria $\mathrm{JC}$ and Besse B: Association of the lung immune prognostic index with immune checkpoint inhibitor outcomes in patients with advanced non-small cell lung cancer. JAMA Oncol 4: 351-357, 2018. PMID: 29327044. DOI: 10.1001/jamaoncol. 2017.4771

17 Faivre-Finn C, Snee M, Ashcroft L, Appel W, Barlesi F, Bhatnagar A, Bezjak A, Cardenal F, Fournel P, Harden S, Le Pechoux C, McMenemin R, Mohammed N, O'Brien M, Pantarotto J, Surmont V, Van Meerbeeck JP, Woll PJ, Lorigan P and Blackhall F: Concurrent once-daily versus twice-daily chemoradiotherapy in patients with limited-stage small-cell lung cancer (CONVERT): An open-label, phase 3, randomised, superiority trial. Lancet Oncol 18: 1116-1125, 2017. PMID: 28642008. DOI: 10.1016/S1470-2045(17)30318-2

18 Paz-Ares L, Dvorkin M, Chen Y, Reinmuth N, Hotta K, Trukhin D, Statsenko G, Hochmair MJ, Özgüroğlu M, Ji JH, Voitko O, Poltoratskiy A, Ponce S, Verderame F, Havel L, Bondarenko I, Kazarnowicz A, Losonczy G, Conev N V., Armstrong J, Byrne $\mathrm{N}$, Shire N, Jiang H, Goldman JW and CASPIAN investigators: Durvalumab plus platinum-etoposide versus platinum-etoposide in first-line treatment of extensive-stage small-cell lung cancer (CASPIAN): A randomised, controlled, open-label, phase 3 trial. Lancet 394: 1929-1939, 2019. PMID: 31590988. DOI: 10.1016/ S0140-6736(19)32222-6

19 Ready N, Farago AF, de Braud F, Atmaca A, Hellmann MD, Schneider JG, Spigel DR, Moreno V, Chau I, Hann CL, Eder JP, Steele NL, Pieters A, Fairchild J and Antonia SJ: Third-line nivolumab monotherapy in recurrent SCLC: CheckMate 032. J
Thorac Oncol 14: 237-244, 2019. PMID: 30316010. DOI: 10.1016/j.jtho.2018.10.003

20 Chung HC, Piha-Paul SA, Lopez-Martin J, Schellens JHM, Kao S, Miller WH, Delord JP, Gao B, Planchard D, Gottfried M, Zer A, Jalal SI, Penel N, Mehnert JM, Matos I, Bennouna J, Kim DW, Xu L, Krishnan S, Norwood K and Ott PA: Pembrolizumab after two or more lines of previous therapy in patients with recurrent or metastatic SCLC: Results from the KEYNOTE-028 and KEYNOTE-158 studies. J Thorac Oncol 15: 618-627, 2020. PMID: 31870883. DOI: 10.1016/j.jtho.2019.12.109

21 Li SJ, Zhao L, Wang HY, Zhou HN, Ju J, Du H and Che GW: Gustave Roussy immune score based on a three-category risk assessment scale serves as a novel and effective prognostic indicator for surgically resectable early-stage non-small-cell lung cancer: A propensity score matching retrospective cohort study. Int J Surg 84: 25-40, 2020. PMID: 33086147. DOI: 10.1016/ j.ijsu.2020.10.015

22 Feng JF, Wang L, Yang X and Chen S: Gustave Roussy immune score (GRIm-Score) is a prognostic marker in patients with resectable esophageal squamous cell carcinoma. J Cancer 11: 1334-1340, 2020. PMID: 32047540. DOI: 10.7150/jca.37898

23 Galvano A, Peri M, Guarini AA, Castiglia M, Grassadonia A, De Tursi M, Irtelli L, Rizzo S, Bertani A, Gristina V, Barraco N, Russo A, Natoli C and Bazan V: Analysis of systemic inflammatory biomarkers in neuroendocrine carcinomas of the lung: Prognostic and predictive significance of NLR, LDH, ALI, and LIPI score. Ther Adv Med Oncol 12, 2020. PMID: 32849916. DOI: $10.1177 / 1758835920942378$

24 Nakaya A, Kurata T, Yoshioka H, Takeyasu Y, Niki M, Kibata K, Satsutani N, Ogata M, Miyara T and Nomura S: Neutrophilto-lymphocyte ratio as an early marker of outcomes in patients with advanced non-small-cell lung cancer treated with nivolumab. Int $\mathrm{J}$ Clin Oncol 23: 634-640, 2018. PMID: 29442281. DOI: $10.1007 / \mathrm{s} 10147-018-1250-2$

25 Suh KJ, Kim SH, Kim YJ, Kim M, Keam B, Kim TM, Kim DW, Heo DS and Lee JS: Post-treatment neutrophil-to-lymphocyte ratio at week 6 is prognostic in patients with advanced non-small cell lung cancers treated with anti-PD-1 antibody. Cancer Immunol Immunother 67: 459-470, 2018. PMID: 29204702. DOI: $10.1007 / \mathrm{s} 00262-017-2092-x$

26 Kaesmann L, Janssen S, Schild SE and Rades D: Value of comorbidity scales for predicting survival after radiochemotherapy of small cell lung cancer. Lung 194: 295298, 2016. PMID: 26883133. DOI: 10.1007/s00408-016-9857-4

27 Käsmann L, Abdo R, Eze C, Dantes M, Taugner J, Gennen K, Roengvoraphoj O, Rades D, Belka C and Manapov F: External validation of a survival score for limited-stage small cell lung cancer patients treated with chemoradiotherapy. Lung 198: 201-206, 2020. PMID: 31897594. DOI: 10.1007/s00408-01900312-6

28 Rades D, Kaesmann L, Janssen S and Schild SE: A new score for estimating survival after definitive radiochemotherapy of limited disease small cell lung cancers. Lung 194: 625-629, 2016. PMID: 27140191. DOI: 10.1007/s00408-016-9886-Z

29 Käsmann L, Eze C, Taugner J and Manapov F: In regards to Chu et al:: Patterns of brain metastasis immediately before prophylactic cranial irradiation (PCI): Implications for PCI optimization in limited-stage small cell lung cancer. Radiat Oncol 15: 252, 2020. PMID: 33138845. DOI: 10.1186/s13014020-01680-7 
30 Ross HJ, Hu C, Higgins KA, Jabbour SK, Kozono DE, Owonikoko TK, Movsas B, Solberg T, Xiao C, Williams TM, Welsh JW, Simko J, Wang XF, Mohindra NA, Hsu C, Stinchcombe T and Bradley J: NRG Oncology/Alliance LU005: A phase II/III randomized clinical trial of chemoradiation versus chemoradiation plus atezolizumab in limited stage small cell lung cancer. J Clin Oncol 38: TPS9082-TPS9082, 2020. DOI: 10.1200/jco.2020.38.15_suppl.tps9082

31 Senan S, Okamoto I, Lee G won, Chen Y, Niho S, Mak G, Yao W, Shire N, Jiang H and Cho BC: Design and rationale for a phase iii, randomized, placebo-controlled trial of durvalumab with or without tremelimumab after concurrent chemoradiotherapy for patients with limited-stage small-cell lung cancer: the ADRIATIC study. Clin Lung Cancer 21: e84-e88, 2020. PMID: 31948903. DOI: 10.1016/j.cllc.2019.12.006

Received November 22, 2020

Revised December 10, 2020

Accepted December 21, 2020 